\title{
p.Ser252Trp and p.Pro253Arg mutations in FGFR2 gene causing Apert syndrome: the first clinical and molecular report of Indonesian patients
}

\author{
Farmaditya EP Mundhofir ${ }^{1}$, MD, PhD, Erik A Sistermans ${ }^{2}$, PhD, Sultana MH Faradz ${ }^{1}$, MD, PhD, Ben CJ Hamel ${ }^{3}$, MD, PhD
}

\begin{abstract}
Apert syndrome (AS) is a rare autosomal dominant disorder characterised by craniosynostosis and limb malformations, and is associated with congenital heart disease and other systemic malformations, including intellectual disability. We report two Indonesian patients with AS, in whom molecular analysis detected p.Ser252Trp (c.755C >G) and p.Pro253Arg (c.758C>G) mutations in the fibroblast growth factor receptor 2 (FGFR2) gene, respectively. Although the syndrome has been frequently described, this is the first clinical report of AS confirmed by molecular analysis in Indonesia. The difference in severity of clinical features in the two patients may be consistent with a genotype-phenotype correlation of the FGFR2 mutation. The management of individuals with AS is best achieved within a multidisciplinary setting. However, in most developing countries, early intervention may be delayed due to late diagnosis, a lack of facilities and financial constraints. This report underpins the benefits of early diagnosis for AS management.
\end{abstract}

Keywords: Apert syndrome, FGFR2, Indonesia

\section{INTRODUCTION}

Apert syndrome (AS) is one of the most severe syndromic craniosynostosis syndromes. ${ }^{(1)}$ It presents in utero with premature fusion of the cranial sutures (craniosynostosis) and severe symmetrical syndactyly of the hands and feet. Cerebral, cardiac, tracheal and genitourinary malformations may be present. Additional skeletal manifestations, acne lesions and intellectual disability are common. (2) AS has a reported prevalence of between 1:50,000 and 1:80,000, and the highest prevalence of AS has been reported in Asian populations. ${ }^{(3)}$

Over 300 cases have been reported since the syndrome was first described at the end of the 19th century. ${ }^{(4)}$ AS shows autosomal dominant inheritance, but most cases are sporadic. ${ }^{(5)}$ It was established in 1995 that two mutations, p.Ser252Trp (c.755C >G) and p.Pro253Arg (c.758C >G), within exon IIla of FGFR2 were the main causes of AS. ${ }^{(4)}$ The two mutations are common mutations detected in approximately $85 \%$ and $15 \%$ of patients diagnosed with AS, respectively. Additional causes were subsequently identified, including p.Ser252Phe mutation, A to G transition at the $3^{\prime}$ acceptor splice site of the intron adjacent to exon IIIc, a partial gene deletion and an Alu element insertion. ${ }^{(6,7)}$

We report two patients with AS, in whom molecular analysis detected p.Ser252Trp and p.Pro253Arg mutations in the FGFR2 gene, respectively. This is the first report that details both clinically and molecularly diagnosed AS in Indonesia.

\section{CASE REPORTS}

Case 1

Patient 1, a male baby born after an uneventful pregnancy to a healthy 34-year-old Javanese mother and a 35-year-old Javanese father, had no contributory family history. Delivery was by Caesarean section due to polyhydramnios at term, and the Apgar scores were 5, 7 and 8 at one, five and ten minutes, respectively. Birth weight was 3,300 g (50th centile), length was $50 \mathrm{~cm}$ (25th centile) and head circumference was $35 \mathrm{~cm}$ (25th centile). Physical examination at birth showed a brachycephalic skull, prominent forehead, midfacial hypoplasia, severe proptosis, downslanting palpebral fissures, low-set posteriorly rotated ears and high arched palate (Fig. 1). The anterior fontanel was $6 \mathrm{~cm} \times 3 \mathrm{~cm}$ in diameter. The posterior fontanel was larger than the anterior fontanel, but the longest distance could not be measured due to the irregular shape. Widely spaced nipples, a systolic ejection murmur of grade III/6 and undescended testes were present. Bilateral, symmetrical cutaneous syndactyly, involving the second to fourth fingers, was present, and the thumbs were found to be broad. Both feet showed symmetrical cutaneous syndactyly of the first to fifth toes, as well as broad halluces.

Cardiac ultrasonographic examination detected the presence of an atrial septal defect (ASD) that was $2 \mathrm{~cm}$ in diameter. Cerebral computed tomography revealed enlarged fontanels and a decreased anteroposterior diameter of the skull. The coronal and sagittal sutures were fused, but the lambdoid sutures were still patent. A clinical diagnosis of AS was made based on these findings. The patient died at 11 months of age due to severe pneumonia.

\section{Case 2}

Patient 2 was a three-month-old male baby born after an uneventful pregnancy to a healthy, nonconsanguineous 18-year-old

\footnotetext{
${ }^{1}$ Division of Human Genetics, Centre for Biomedical Research (CEBIOR), Faculty of Medicine, Diponegoro University, Semarang, Indonesia, ${ }^{2}$ Department of Clinical Genetics, VU University Medical Centre, Amsterdam, ${ }^{3}$ Department of Human Genetics, Radboud University Nijmegen Medical Centre, Nijmegen, The Netherlands

Correspondence: Prof Sultana MH Faradz, Professor, Centre for Biomedical Research (CEBIOR), Faculty of Medicine, Diponegoro University, GSG 2nd floor JI Dr Sutomo 14, Semarang, 50241, Indonesia. sultana@indosat.net.id
} 

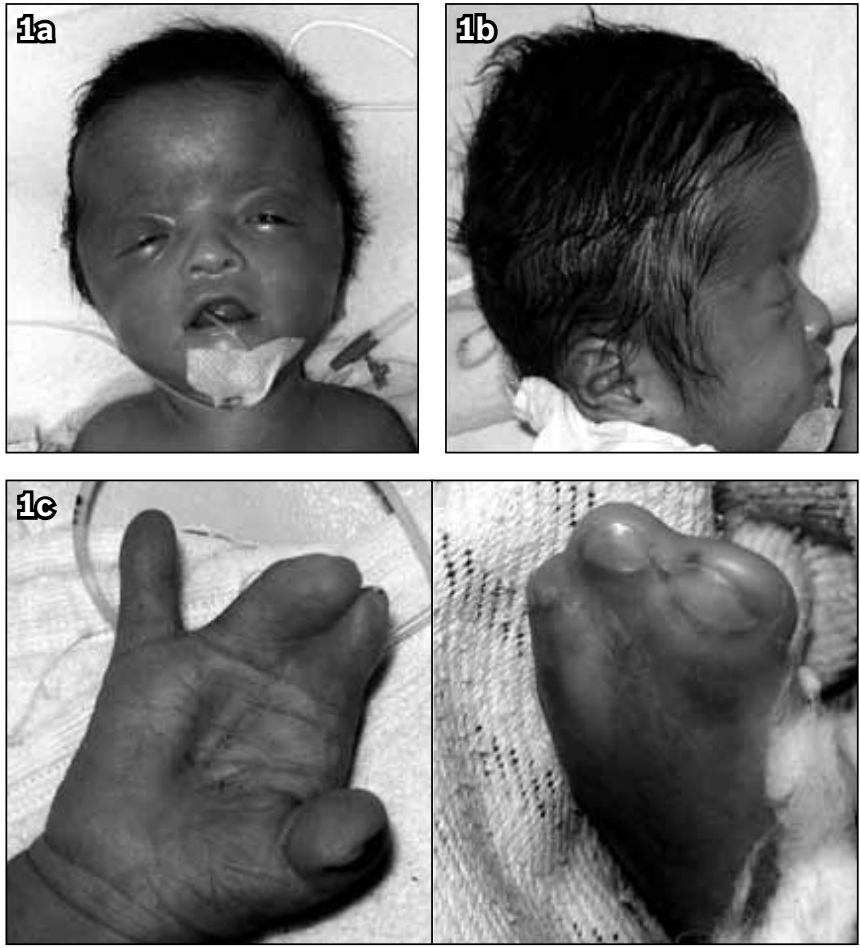

Fig. 1 Patient 1 at the age of one month when p.Ser252Trp (c.755C>G) mutation was identified. Photographs show (a) facial dysmorphisms, which include midfacial hypoplasia, severe proptosis, hypertelorism and downslanting of palpebral fissures; (b) a brachycephalic skull, frontal bossing and low-set posteriorly rotated ears; and (c) symmetrical syndactyly of the hands and feet.

Javanese mother and 19-year-old Javanese father. There was no contributory family history. Delivery was spontaneous at 37 weeks of pregnancy. The patient had a birth weight of 2,700 g (5th-10th centile), with a length of $52 \mathrm{~cm}$ (75th centile). His hearing, vision and development were normal. Clinical examination detected frontal bossing, ptosis, hypertelorism, midfacial hypoplasia, large ears, depressed nasal bridge, anteverted nostrils, thin upper lip and high palate. The skull was turribrachycephalic, and bilateral coronal and metopic synostoses were present. Bilateral hand syndactyly of all the digits and bilateral syndactyly of all the toes were also present, in addition to broad and short halluces (Fig. 2). A diagnosis of AS was made based on these clinical features.

Radiographs of both hands confirmed soft tissue syndactyly of all the digits. Bony fusion of the distal phalanges was suspected, although this could not be confirmed due to digital crowding. It appeared that bony fusion of the fourth and fifth distal phalanges, and complete fusion of the second and third distal phalanges of the right hand were most likely present. It was also likely that distal fusion of the second and fifth distal phalanges of the left hand was present. Radiographs of both feet confirmed soft tissue syndactyly of all the toes, small distal phalanges and delta phalanges of the great toes. Skull radiographs detected fused coronal sutures, turribrachycephalic skull contour, small anterior fontanel, short anteroposterior diameter of the skull and flat, elongated forehead. Patient 2 died at 18 months of age due to upper airway obstruction.
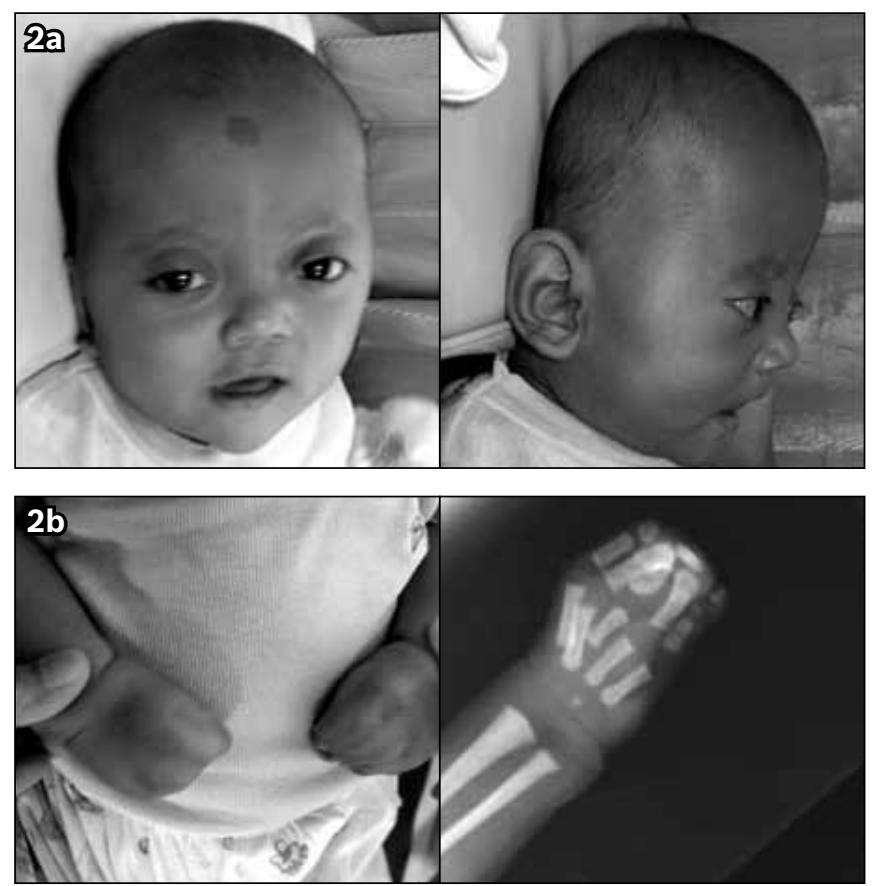

Fig. 2 Patient 2 at the age of three months when p.Pro253Arg (c.758C>G) mutation was detected. (a) Photographs show facial dysmorphisms, which include a brachycephalic skull, bicoronal craniosynostosis, frontal bossing, exophthalmus, hypertelorism, midfacial hypoplasia, depressed nasal bridge, anteverted nostrils and thin upper lip. (b) Photograph and radiograph show typical AS hand type III. Note the soft tissue syndactyly. Bony fusion of the distal phalanges was suspected, but could not be confirmed due to digital crowding.

\section{Mutation Analysis}

Mutation analysis was conducted in both patients. DNA was isolated from peripheral blood using the salt saturation method, as previously described by Miller et al. ${ }^{(8)}$ Molecular genetics analysis of FGFR2, targeting the exon coding for p.Ser252Trp and p.Pro253Arg, was performed by direct sequencing. The genomic DNA reference sequence used was NM_000141.4. Polymerase chain reaction (PCR) of exon 7 was performed using the primers GGTCTCTCATTCTCCCATCCC (forward) and CCAACAGGAAATCAAAGAACC (reverse), resulting in a $325 \mathrm{bp}$ fragment. $20 \mathrm{ng}$ of DNA solution $(5 \mu \mathrm{L})$ was added to $20 \mu \mathrm{L}$ of PCR mixture. This PCR mixture contained $0.2 \mu \mathrm{L}$ of $25 \mathrm{mM}$ deoxyribonucleotide triphosphates (dNTPs), $0.75 \mu \mathrm{L}$ of $1.5 \mathrm{mM} \mathrm{MgCl}_{2}, 1 \mu \mathrm{L}$ of $10 \mathrm{pmol} / \mu \mathrm{L}$ for each primer, $2.5 \mu \mathrm{L}$ of 10X PCR buffer, $0.2 \mu \mathrm{L}$ of $5 \mathrm{U} / \mu \mathrm{L}$ Platinum ${ }^{\circledR}$ high fidelity Taq DNA polymerase, and $15.35 \mu \mathrm{L}$ of $\mathrm{H}_{2} \mathrm{O}$. PCR was initiated with denaturation at $94^{\circ} \mathrm{C}$ for 5 minutes, followed by 35 PCR cycles (at $94^{\circ} \mathrm{C}$ for 30 seconds, $60^{\circ} \mathrm{C}$ for 30 seconds, and $72^{\circ} \mathrm{C}$ for 30 seconds). After control on agarose gel, $5 \mu \mathrm{L}$ of the PCR product was used for the sequence reaction (BigDye Terminator Cycle Sequencing Kit version 3.3; Applied Biosystems, Foster City, CA, USA) on an ABI 3730 Genetic Analyzer (Applied Biosystems, Foster City, CA, USA), following the manufacturer's directions. Sequencing was performed bidirectionally using the forward and reverse PCR primers.

In Patient 1, p.Ser252Trp (c.755C>G) mutation was detected, while p.Pro253Arg (c.758C >G) mutation was detected in 
Table I. Genotype, phenotype and parental age of Patients 1 and 2.

\begin{tabular}{|c|c|c|c|c|c|c|c|}
\hline \multirow[t]{2}{*}{ Patient } & \multirow[t]{2}{*}{ Gender } & \multirow[t]{2}{*}{ Genotype } & \multicolumn{3}{|c|}{ Phenotype } & \multicolumn{2}{|c|}{ Parental Age (yrs) } \\
\hline & & & $\begin{array}{l}\text { Craniofacial } \\
\text { Severity score* }\end{array}$ & Hand syndactyly & Foot syndactyly & Paternal & Maternal \\
\hline 2 & Male & p.Pro253Arg & 1 & Spoon hand & Spoon feet & 19 & 18 \\
\hline
\end{tabular}

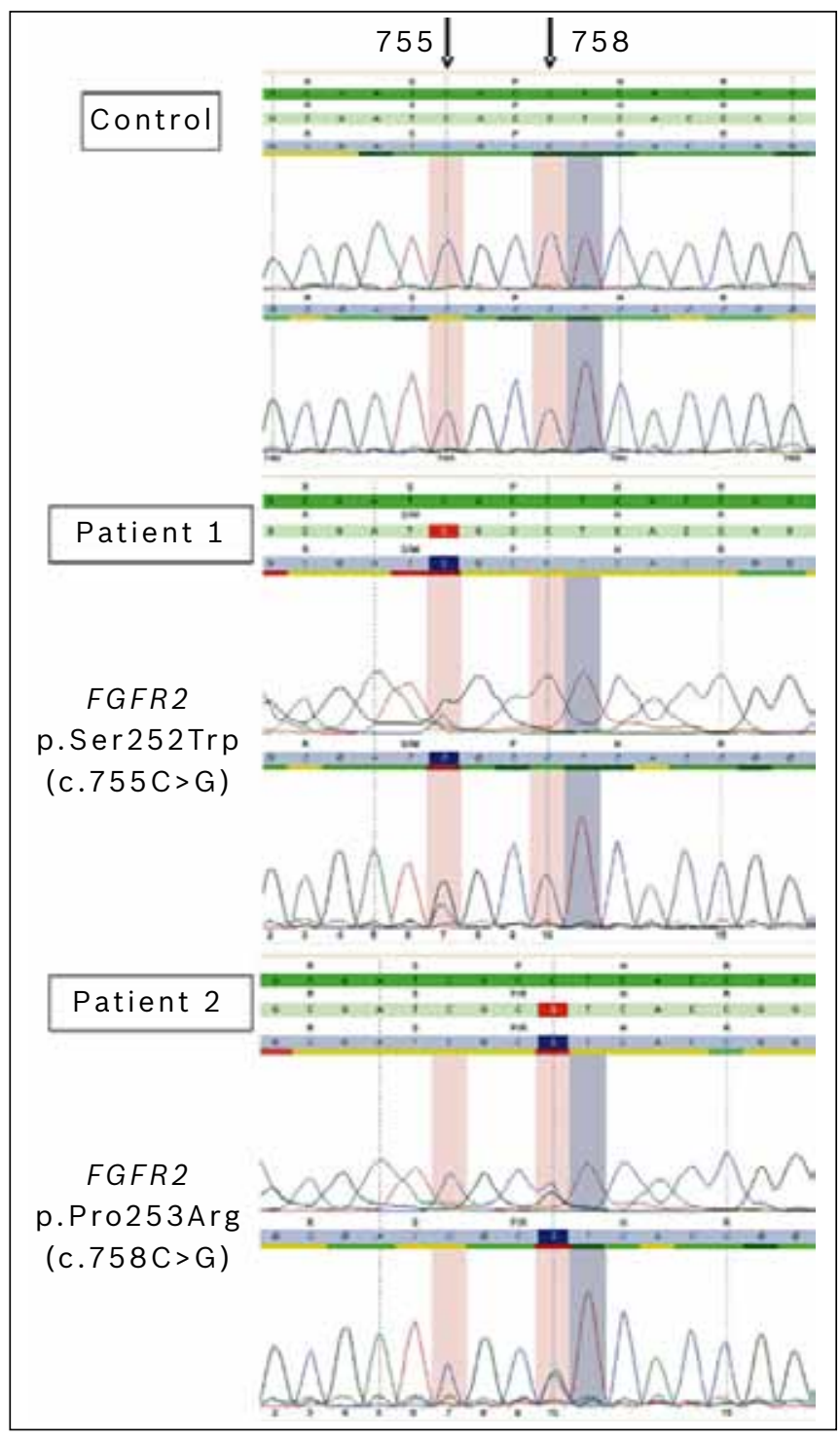

Fig. 3 Sequencing results of patients 1 and 2 show p.Ser252Trp mutation (c.755C>G) and p.Pro253Arg mutation (c.758C>G), respectively. The analysis software (Sequence Pilot) indicates known pathogenic variants with a pink bar, and known nonpathogenic variants with a gray bar.

Note: The upper lane is the forward read and the lower lane is the reverse read (conversed to make it similar to forward).

Patient 2 (Fig. 3). The parents of the two patients did not undergo any molecular testing, as they had no features of AS.

\section{DISCUSSION}

This is the first report of diagnosis of AS confirmed by molecular genetic testing in Indonesia. The presence of FGFR2 mutations, p.Ser252Trp and p.Pro253Arg, was consistent with the diagnosis of AS. The mutations were concluded to have occurred de novo, as the parents of both patients had no features of AS, although germline mosaicism could not be excluded. p.Ser252Trp and p.Pro253Arg mutations account for more than $99 \%$ of the mutations in $\mathrm{AS}^{(6,7)}$ However, these two common mutations do not account for all cases of AS. Therefore, further analysis of the entire gene is recommended in order to find mutations that are potentially specific to the Indonesian population.

Compared to patients with p.Pro253Arg mutation, those with p.Ser252Trp mutation are more likely to have a cleft palate. In contrast, hand and foot syndactylies have been reported to be more severe in patients with p.Pro253Arg mutation than in those with p.Ser252Trp mutation. ${ }^{(9-11)}$ Although neither of our patients had a cleft palate, Patient 1 (with p.Ser252Trp mutation) had a more severe craniofacial phenotype and less severe syndactyly than Patient 2 (with p.Pro253Arg mutation) (Table I). Although this sample size is small, it is consistent with the reported clinical spectrum of the most common mutations described in AS.

Moloney et al described a paternal age effect (PAE) in $\mathrm{AS}^{(12)}$ which has been confirmed in another germ cell study. ${ }^{(5)}$ The mutation rate in males is higher than that in females due to the occurrence of repeated divisions of spermatogonia in males. In the two cases described, PAE due to an increased mutation frequency caused by an older paternal age might be possible in Patient 1, whose father was 35 years old. This is not the case for Patient 2, whose father was younger (19 years old). However, it was suggested that other factors, such as environmental factors, could contribute to the mutation rate of the father's sperm. ${ }^{(5)}$

Prenatal ultrasonographic findings associated with AS have been documented. With the advances in 3D ultrasonography, typical enlargement of the metopic suture in AS may be detected in utero. ${ }^{(13)}$ Prenatal ultrasonographic diagnosis of AS is usually made in the presence of a triad of clinical signs - bilateral syndactyly of the hands, midfacial hypoplasia and abnormal cranial shape with hypertelorism. ${ }^{(13)}$ However, many cases of AS are not prenatally diagnosed until the third trimester when the craniofacial abnormalities are more obvious. ${ }^{(14)}$ Prenatal ultrasonographic examination for early diagnosis was not available for the mothers of our two patients.

Patients with AS are best managed within a multidisciplinary setting. Alterations in cranial shape due to multiple craniosynostoses can limit cerebral growth and development secondary to raised intracranial pressure. Therefore, early surgery to prevent complications is advocated by many craniofacial centres. ${ }^{(15)}$ Fronto-orbital advancement is a commonly used technique in 
craniofacial surgery. This technique comprises bifrontal craniotomy with bilateral removal of the frontal bones, together with the removal of the supraorbital region. ${ }^{(15)}$ Following that, additional craniofacial interventions may need to be carried out to treat midface retrusion and dental malocclusion. In general, the most important management for AS patients comprises immediate craniotomy, hand and feet surgery, and long-term follow-up. However, in most developing countries, early intervention is hampered by late diagnosis, a lack of facilities and financial constraints. Although AS can be diagnosed and managed without molecular diagnostics, its availability for craniofacial disorders in Indonesia will promote early comprehensive management of patients with AS in the local setting.

\section{ACKNOWLEDGEMENTS}

The authors thank the following: Wistiani, Asri Purwanti and Kamilah Budhi Rahardjani for referral of the patient; Resie Vervenne for the preparation of Fig. 3; Carlo Marcelis for the radiologic review; and Tri Indah Winarni, Bregje van Bon and Tony Roscioli for their critical review of the manuscript. The authors also thank the laboratory staff at VU Medical Centre, The Netherlands and CEBIOR Faculty of Medicine Diponegoro University, Semarang, Indonesia. The study grant was funded by the RISBIN-IPTEKDOK 2007/2008 programme, Department of Health, Republic of Indonesia.

\section{REFERENCES}

1. Gorlin RJ, Cohen MM Jr, Hennekam RCM. Syndromes of the Head and Neck. 4th ed. Oxford: Oxford University Press, 2002.

2. Cohen MM, Kreiborg S. The Central Nervous System in the Apert
Syndrome. Am J Med Genet 1990; 35:36-45.

3. Tolarova MM, Harris JA, Ordway DE, Vargervik K. Birth prevalence, mutation rate, sex ratio, parents' age, and ethnicity in Apert syndrome. Am J Med Genet 1997; 72:394-8.

4. Wilkie AO, Slaney SF, Oldridge M, et al. Apert syndrome results from localized mutations of FGFR2 and is allelic with Crouzon syndrome. Nat Genet 1995; 9:165-72.

5. Glaser RL, Broman KW, Schulman RL, et al. The paternal-age effect in Apert syndrome is due, in part, to the increased frequency of mutations in sperm. Am J Hum Genet 2003; 73:939-47.

6. Bochukova EG, Roscioli T, Hedges DJ, et al. Rare mutations of FGFR2 causing apert syndrome: identification of the first partial gene deletion, and an Alu element insertion from a new subfamily. Hum Mutat 2009; 30:204-11.

7. Oldridge M, Zackai EH, Donald-McGinn DM, et al. De novo alu-element insertions in FGFR2 identify a distinct pathological basis for Apert syndrome. Am J Hum Genet 1999; 64:446-61.

8. Miller SA, Dykes DD, Polesky HF. A simple salting out procedure for extracting DNA from human nucleated cells. Nucleic Acids Res 1988; 16:1215.

9. Lajeunie E, Cameron R, El Ghouzzi V, et al. Clinical variability in patients with Apert's syndrome. J Neurosurg 1999; 90:443-7.

10. Slaney SF, Oldridge M, Hurst JA, et al. Differential effects of FGFR2 mutations on syndactyly and cleft palate in Apert syndrome. Am J Hum Genet 1996; 58:923-32.

11. von Gernet S, Golla A, Ehrenfels Y, Schuffenhauer S, Fairley JD. Genotypephenotype analysis in Apert syndrome suggests opposite effects of the two recurrent mutations on syndactyly and outcome of craniofacial surgery. Clin Genet 2000; 57:137-9.

12. Moloney DM, Slaney SF, Oldridge M, et al. Exclusive paternal origin of new mutations in Apert syndrome. Nat Genet 1996; 13:48-53.

13. Athanasiadis AP, Zafrakas M, Polychronou $\mathrm{P}$, et al. Apert syndrome: the current role of prenatal ultrasound and genetic analysis in diagnosis and counselling. Fetal Diagn Ther 2008; 24:495-98.

14. David AL, Turnbull C, Scott R, et al. Diagnosis of Apert syndrome in the second-trimester using 2D and 3D ultrasound. Prenat Diagn 2007; 27:629-32.

15. Marucci DD, Dunaway DJ, Jones BM, Hayward RD. Raised intracranial pressure in Apert syndrome. Plast Reconstr Surg 2008; 122:1162-8. 